Recebido: $11 / 08 / 2015$

Aprovado: 16/08/2015

\title{
A religiosidade no bem morrer: em busca de uma teoria explícita do sagrado
}

Daniel Martins Ferreira*

Resumo: A salvação das almas, desde o período medieval, ocupa um lugar central na doutrina católica em constante construção. Durante a era moderna, no reino português e em seus domínios, os livros devocionais que ensinam o fiel a como se preparar para a morte nos servem como indícios do modo de pensar de uma elite clerical e suas orientações os fiéis, leigos ou não. A administração do sagrado pelos sacerdotes parece ser um elemento constituidor, não apenas do culto e de sua liturgia, mas de uma sociedade que se orienta pelo inculcamento de valores cristãos. Este artigo debate sobre a presença do sagrado naqueles livros e como aquele que os pesquisa necessariamente utilizará uma teoria do sagrado, ainda que implícita e inconscientemente. Da mesma forma, compara abordagens diferentes do sagrado, com o interesse final de concluir por uma teoria explícita do sagrado, conscientemente.

Palavras-chave: Sagrado; Bem morrer; Império Português

Abstract: The salvation of souls, since the medieval period, occupies a central place in the catholic doctrine under constant construction. During the modern era in the Portuguese Empire and its domains, the devotional books teaching the belivers how to prepare for death serve us as evidence of the way of thinking of a clergy elite and their guidances to the faithful, layman or not. The administration of the sacred by the priests looks like a constitutor element, not only of the cult and it's liturgy, but of a society that guides itself through the inculcation of christian values. This article debates the presence of the sacred in those books and how the ones researching them will necessarily use a sacred's theory, even implicitly and subconsciously. Similarly, compares different approaches of the sacred, with the goal of concluding for an explicit theory of the sacred, consciously.

Keywords: Sacred, Well dying, Portuguese Empire

\footnotetext{
* Mestrando vinculado ao Programa de Pós-Graduação em História pela Universidade de Brasília. E-mail: danielmartinsferreira@gmail.com
} 
Este artigo tem por interesse uma análise bibliográfica sobre o conceito de sagrado, em apoio ao estudo do discurso religioso católico português do bem morrer, na era moderna. O objetivo final é delimitar um entendimento que, sem pretensão universal, seja operacional para a referida pesquisa. Iniciarei falando um pouco sobre a pesquisa que tenho desenvolvido e que me levou à questão sobre o sagrado, para então trazer à análise alguns autores que também pensaram este conceito como relevante para uma compreensão da realidade humana e, por fim, pretendo sinalizar uma conceituação a ser utilizada na referida pesquisa, em diálogo com discussão análogo conduzida por Leandro Rust.

Tendo por objeto o discurso eclesiástico católico sobre a salvação das almas, no Império Português Ultramarino, encontrei nos manuais devocionais que ensinavam a arte do bem morrer, uma fonte vital. São obras com uma forte inclinação prática, com muitas orientações destinadas a um público leigo, ainda que também fossem manuseados por sacerdotes, e com uma mensagem religiosa clara: a morte é certa e sua hora é incerta e é necessário que se esteja preparado corretamente para este acontecimento, uma vez que isto definirá o destino das almas, de forma final e com efeitos permanentes.

Esse discurso goza de uma permanência considerável, podendo ser traçada uma linha que se inicia no século XIV até o século XIX, dois marcos temporais que não devem ser tratados em termos de datas exatas, mas como aproximações dos períodos de transformações de mentalidades e práticas do homem em relação à morte.

O primeiro marco trata da alteração na concepção de juízo final coletivo para juízo final individual, em que existe um novo momento de luta pela salvação ou danação das almas, não mais apenas no fim dos tempos - na grande teleologia cristã -, mas também no momento da morte de cada um, em que um julgamento prévio determinaria o local em que a alma aguardaria o segundo julgamento, este, sim, coletivo e de toda a humanidade. Com este julgamento individual, a possibilidade do purgatório assume papel central, ampliando o papel do indivíduo sobre sua salvação. Neste sentido, surgem a artes moriendi, manuais devocionais que tem por finalidade educar o leitor sobre a morte e como se preparar para a mesma.

Mas esses manuais irão se alterar com o tempo, em seu conteúdo e forma, e não existem alheios às influências históricas. Assim, considero como um segundo marco a secularização (Rodrigues 2005), a descristianização de atos que foram durante um longo período colocados sob tutela e controle da Igreja. 
Mas não podemos esquecer o tempo longo, os dez séculos de duração durante os quais o purgatório passou de uma conquista para, ao mesmo tempo, tornar-se um instrumento ambíguo de controle social e ideológico, e também, olhando de baixo, o reconhecimento assumido do pecado do qual precisa purgar-se por própria conta, assim como tentam livrar-se dos mortos. Essa leitura culpabilizante foi se desfazendo nos últimos dois séculos, suscitando desde a era das Luzes (a do século XVIII) novas estratégias, progressivamente emancipadas do discurso religioso oficial, estratégias por meio das quais os homens tentam gerir o trabalho do luto, sempre renovado(Vovelle 2010: p. 326)

Acompanhando Vovelle, o que parece evidente é a existência de um discurso católico relacionado a um imaginário em construção e que vai sendo, aos poucos, transformado, atendendo aos embates e interesses sociais e ideológicos e, em um tempo mais próximo do nosso presente, um discurso que vai sendo abandonado em benefício de outras representações e estratégias para se conduzir a relação com a morte. Porém, reconhecendo a existência desse discurso e escolhendo estudá-lo, percebo que não tratamos apenas de um esforço alegórico e metafórico, mas uma tentativa de expressão de uma cosmologia, com elementos simbólicos, sim, mas em busca da definição de um espaço que é real e sagrado e com consequências graves para o indivíduo e toda a humanidade. Mas o que significa chamar esse espaço de sagrado?

Com esta pergunta em mente, considero ser vital tentar uma resposta e estabelecer de forma clara, o conceito de sagrado. Sem intenções universalizantes, mas colocar em diálogo formas diferentes de se considerar e entender o sagrado e, quem sabe então, alcançar uma definição que seja, no mínimo, operacional para se estudar o discurso católico do bem morrer. Esta mesma preocupação pode ser verificada abaixo, e por ela iniciaremos a análise:

Coexistindo na historiografia como adversário jurados, a Reforma Gregoriana e a Revolução Papal mantiveram sempre algo comum: uma teoria implícita do sagrado. Nas duas abordagens, o clero papal é caracterizado pela mesma experiência acerca da essência da religião. Nos dois casos, os eclesiásticos vinculados ao poder papal surgem escritos com base em uma postura reincidente. A religião os teria dotado de um horizonte global de sentidos sobre a sociedade a sua volta. Os historiadores quase se engalfinharam ao tentar explicar o processo gerador das convicções reformadoras. Os pesquisadores que as explicavam como o último estágio da evolução do pensamento religioso sentiam-se afrontadas pelos autores que as definiam como repercussões políticas de acontecimentos inesperados (Rust 2013: p. 85).

Como reflexão da fala acima de Rust, considero que não apenas a historiografia da reforma papal terá uma teoria implícita do sagrado ao manejar este objeto, ou seja, o sagrado.

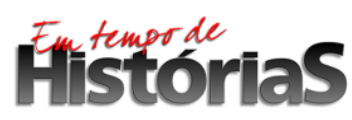


Podemos pensar este como resultado de escolhas intencionais de uma elite ou observá-lo como a confluência moral de uma época ou, ainda, talvez reduzir a escala de sua importância a simples manifestações de movimentos mais profundos e irracionais - cada escolha trará consequências diferentes, conformando tacitamente a pesquisa aos silogismos inerentes a cada entendimento. Assim, a indefinição ou a imprecisão conceitual torna difícil a verificação dos caminhos epistemológicos assumidos, sendo conveniente e necessário trabalhar em direção ao seu esclarecimento.

Mas se a precisão conceitual é importante, não espero aqui esgotar os sentidos possíveis de sagrado. Haverá um breve momento para um panorama de ideias sobre a sacralidade e aqueles que tentaram oferecer uma definição, assim como um diálogo com aqueles que, como eu, tem por objeto o discurso sobre a salvação das almas, assim como as práticas e atitudes diante da morte.

Nas sociedades mais desenvolvidas, como disse, a busca de ajuda em sistemas de crenças sobrenaturais contra o perigo e a morte se tornou menos apaixonada; em certa medida, transferiu sua base para sistemas seculares de crenças(Elias 2001: p. 13)

Esta citação é proveniente do livro A Solidão dos Moribundos, do sociólogo Norbert Elias, uma obra que presa por reflexões sobre a mortalidade, a morte e o envelhecer, alternando entre um panorama histórico e análises da contemporaneidade, que é o foco do trecho acima. Ainda que não sendo seu tema, a consequência de seu pensamento é que os sistemas de crença sobrenaturais servem como ajuda contra o perigo e a morte e que essa ajuda não são exclusividades desses sistemas, uma vez que nas sociedades mais desenvolvidas transferiu-se este suporte para os sistemas seculares de crenças.

As crenças seculares podem ser identificadas com o sagrado? Ou seria o elemento sobrenatural vital para isto? Elias não nos responderá, mas por enquanto bastará manter a sugestão em mente desta divisão dialética dentro do gênero crenças, de um lado as sobrenaturais, do outro as seculares. Nesta primeira tentativa de definição, o sagrado cumpre a função de ter a utilidade de resguardar a sociedade contra perigos concretos. Claro, não se fala de resguardar fisicamente a sociedade contra a morte, mas os sistemas de crenças auxiliariam a controlar as emoções. Tal como estabilizadores de emoções e condutores de práticas, evitando os picos do desespero ou os baixios da depressão e falta de ação. É isto que compreendo, por exemplo, da alusão de Elias quanto aos efeitos prejudiciais da ausência do trabalho de luto ou de sua condução em exagero, ambos podendo resultar em danos físicos ou 
sociais irreversíveis e finais. De certa forma, os ritos em relação à morte que podem resguardar os viventes da morte física ou social. Com este raciocínio, vejamos um sistema de crenças específico real, que talvez possa contribuir para melhor entender a questão:

A Igreja extraiu grande poder deste novo sistema do além. Ao administrar ou controlar as preces, as esmolas e as missas feitas pelos vivos em favor dos seus mortos, ela teria benefícios, inclusive com a transposição do sistema de indulgências para a esfera da morte e do Purgatório.(Rodrigues 2005: p. 48)

É possível localizar uma similaridade entre Rodrigues e Elias em torno da utilidade do sagrado. E, com as transformações ocorridas na sociedade do Brasil oitocentista, com destaque para a secularização dos ritos funerários, algumas utilidades serão transferidas para outras esferas de ação, a saber, para as mãos do Estado ou sob a tutela familiar em detrimento da curatela eclesiástica. Entretanto, ainda que a obra de Rodrigues não tenha intenção de oferecer uma ideia que diga a respeito de sistemas de crença, de forma geral, reconhece a sua utilização como proteção contra os perigos que a sociedade enfrenta, em um caminho parecido com o de Elias. Contudo, conclui não apenas que o sagrado pode ser útil, ou que pode funcionar como resguardo contra os perigos, mas como ele também foi concretamente utilizado para atingir fins específicos pela Igreja. Ensina sobre a pedagogia do medo, uma ideia desenvolvida pela historiografia acerca de variadas ações da Igreja, desde fins da Idade Média, que buscariam obter reações dos fiéis, por meio da utilização de imagens de medo complementada pela oferta de consolo:

(...) se por um lado a Igreja amedrontava o fiel para que ele se pusesse sob seus ditames, por outro, mostrava o caminho para o conforto, oferecendo-lhe a imagem de um Deus misericordioso, principalmente para que se mostrasse contrito e obediente. (Rodrigues 2005: p. 64)

A Igreja pode amedrontar ou oferecer conforto, o sagrado pode significar fonte de medo, esperança ou ambos. Nesta dialética reside parte de seu poder de persuasão. O medo geraria o estímulo no fiel, de fazer ou de não fazer. Mas apenas o estímulo não seria suficiente sem a condução sobre o que fazer a direção que define o certo, o que causará a proteção do temido. O que não significa dizer que esta utilização do sagrado seja uma construção livre de significados e regras doutrinárias de maneira cínica, como se os próprios postulantes da doutrina, dentro da estrutura eclesiástica, fossem homens livres dos símbolos de fé e seus significados ao seu tempo. Também, não me parece adequado pensar que estes sacerdotes seriam passivos receptáculos do conteúdo da fé e fiéis e pios seguidores de seus ditames. 
Sacerdotes como os que escreveram os manuais que analiso são frutos de seu tempo e por isso carregam fortes marcas e limitações em seu criar e articular, mas também atendem a suas próprias necessidades, vaidades, interesses políticos. José Aires, em 1724, na Bahia, diz que escreve sua obra em virtude de outro livro - de 1701, chamado a A Escola do Bem Morrer (Bonucci 1701) - ter se esgotado. O que ele não expõe é a razão de não ter buscado outras opções, como reeditar aquele livro ou outros tantos à disposição e aos quais poderia ter acesso, possivelmente com menos dificuldade do que a elaboração de nova obra, submissão às aprovações da censura e demais burocracias situadas em Portugal. Suas razões apenas podem ser imaginadas, mas seu interesse de visibilidade ou ainda de conferir as suas próprias impressões sobre o tema são possíveis motivadores. O relevante é registrar que suas motivações não desvinculam sua ação do campo da crença e das mentalidades que compartilhava. E, neste interesse, o sagrado pode apresentar uma representação comum ou uma representação percebida como comum entre diferentes elementos e estratos de um grupo:

O historiador da morte não deve lê-los [os documentos de origem clerical] com as mesmas lentes que o historiador das religiões. Não deve consideralos, conforme se apresentaram no pensamento de seus autores, lições de espiritualidade ou de moralidade. Deve decifrá-los para reencontrar, sob linguagem eclesiástica, o fundo banal de representação comum que era evidente e que tornava a lição inteligível ao público. (Ariès 2012: p. 26)

Com Philippe Ariès pretendo perscrutar melhor as modificações no conteúdo do sagrado, seja ao longo do tempo, seja por seu tratamento por diferentes pontos de uma sociedade, seja por diferentes sociedades/grupos em um mesmo período. A abordagem de Ariès se dá por meio do estudo das mentalidades. Vincula-se a uma metodologia consciente, expressa e por ele defendida (embora sem descartar outras metodologias, como trataremos adiante ao falar de Vovelle), de conferir relevância a elementos mais obscuros da mentalidade, por acreditar que estes elementos se arrastam por longos períodos e movidos por razões que ficam em uma dimensão entre o biológico e o cultural. Vejamos abaixo:

Tenho tendência a desvalorizar a influência dos sistemas religiosos e culturais(...). A Igreja me interessa mais como indicador e revelador de sentimentos despercebidos do que como grupo de pressão que terá comandado os sentimentos em suas origens. A meu ver, as grandes oscilações que arrastam as mentalidades - atitudes diante da vida e da morte - dependem de motores mais secretos, mais subterrâneos, no limite do biológico e do cultural, ou seja, do inconsciente coletivo.(Ariès 2012: p. 279) 
A compreensão do que sejam esses motores mais secretos e o significado exato de biológico e cultural para Ariès apenas podem ser por nós inferidos. O que talvez seja mais distinguível é uma proposta de estudo em que os sistemas religiosos e culturais são menos interessantes enquanto utilidade, ação política ou motivadores da ação humana, mas, sim, como indicadores. A tese implícita (mas explícita no restante da obra de Ariès) é a de que existe algo que conecta todas as pessoas de uma dada época e, por vezes, mesmo ao longo do tempo pelo efeito da continuidade. E esse algo não observa a limitação entre rico e pobre, erudito e ignorante, comandante e subordinado. Existe um conflito entre originalidade e adesão ao conhecido. Relação que Ariès postula ser a conexão entre os diferentes grupos. Afinal, se uma ideia (um discurso, uma obra) for tão original que não seja compreendida pelo conjunto de homens de seu tempo, ela não será julgada original, pois não será assim recebida. Se esta mesma ideia aderir por demais ao pensamento comum, não obterá destaque. A meu ver, estas ideais causam alguns conflitos, especialmente por não considerarem as diferentes teias humanas e políticas que podem levar uma obra pouco compreendida a um lugar social de destaque ou a uma total falta de prestígio.

Mas retomando a atenção ao conceito de sagrado, em que os pensamentos de Ariès podem nos auxiliar? Embora não concorde integralmente com a direção de Ariès, de que se possa ignorar de todo o estudo dos sistemas religiosos, os seus escritos contribuem para assinalar que talvez exista algo além da doutrina firmada e proclamada. A preocupação dele não é, de forma alguma, nos indicar a origem desse algo além, mas apenas estudar suas evidências, século a século, em uma longuíssima duração, do início da era cristã até o século XX. E acredito que esse esforço possa ser abstraído aqui.

Carlo Ginzburg, em diversas de suas obras, também postula uma região de criação de significados humanos e em linguagem bem próxima à de Ariès, pensando também nesta dimensão biológica que afeta a forma como criamos nossos símbolos mais essenciais e como construímos todo o castelo da psique individual, das nossas relações sociais e de nossa expressão linguística. Em O Queijo e os Vermes (Ginzburg 2006) trabalha com o conceito da circularidade de ideias entre os segmentos da elite e os mais populares, encontrando no moleiro Menocchio traços de oralidade, vindos de uma cultura agrária e pagã antiga, e influências de uma cultura escrita diversa. Mas nas obras Os Andarilhos do Bem (Ginzburg 2010) e História Noturna (Ginzburg 2012) é que seu enredo transforma-se e aproxima-se do conceito oferecido por Ariès. Não é apenas a questão da circularidade, ou de fragmentação erudito ou popular. Ou, se retornarmos a Elias, também não se trata de influência sobrenatural 
ou secular; entre o cultural e o biológico; inconsciente coletivo. Ariès e Ginzburg se referem a esses motores secretos pelo termo subterrâneo, Ginzburg fala até de uma história subterrânea.

Deixemos Ariès e Ginzburg por alguns instantes, para trazer à discussão uma forma de trabalhar exemplificada por Michel Vovelle. Assim como Ariès, Vovelle atribui uma mudança lenta às mentalidades e com isto as atitudes em frente ao sobrenatural. Entretanto, Vovelle não toma para si o método impressionista de Ariès, acreditando que uma forte base empírica é importante.

O universo católico da Contrarreforma soube levar vantagem desse dilema fazendo da pastoral da morte, na qual o purgatório, sanção severa mas comedida dos pecados dos homens, tem lugar de destaque, uma das peças capitais de sua reconquista das almas. Aqui podemos inscrever, mais facilmente do que antes, essa realidade da ordem da fé num contexto mais amplo de controle social, relativizando o que cabe à ação voluntária dos clérigos. (Vovelle 2010: p. 323)

A pesquisa de Vovelle, assim como dos demais autores tratados até agora, não é voltada ao sagrado em si, mas as práticas e mentalidades diante da morte. Em específico, aqui, seu foco é o purgatório. Ele retoma ideias já discutidas, como a utilidade do sagrado em Rodrigues, porém, explicita a questão da ação voluntária dos clérigos, apresentando-se com um contraponto direto a Ariès, ainda assim, relativizando a ação individual dos membros do clero dentro de elementos macro, como o contexto mais amplo de controle social.

Neste ponto, creio ser necessária uma breve digressão. Se este artigo tem por objetivo a discussão do conceito de sagrado e como pode ser utilizado para o estudo do discurso soteriológico, passamos até agora por Elias, Rodrigues, Ariès, Ginzburg e Vovelle, buscando em seus trabalhos noções implícitas, as teorias implícitas do sagrado, mas ainda nos faltam algumas opiniões daqueles que trabalharam diretamente esse mesmo conceito, opiniões essas que colocarei em destaque.

Aqui, retomarei a exposição do professor Leandro Rust, em seu livro A Reforma Papal (1050-1150), tentando reconstruir suas linhas de pensamento e a partir de suas conclusões, tecer algumas considerações.

No capítulo chamado As pegadas do sagrado: o político como religiosidade, Rust pinta o quadro da discussão conceitual entre os teóricos da revolução papal e os da reforma gregoriana. Não nos interessará entrar nos pormenores desse debate, mas sim, considerar que é a partir dessa discussão que ele buscará compreender as acepções implícitas da sacralidade. E é no panorama teórico que se constrói que situarei minha análise. 
A sua árvore de conceitos passará por Durkheim, Mircea Eliade, Roger Caillois, Rudolf Otto, Franco Ferrarotti e Maurice Godelier (Rust 2013: pp. 101-113). Outros autores também são por ele citados, mas não ocupam os focos do debate e não serão aqui discutidos.

A primeira contribuição será então de Durkheim. O sagrado seria marcado por uma ambivalência entre dois domínios opostos, um de forças benfazejas, outro de forças más $e$ impuras. O sagrado seria "o nome que cabe a esse conjunto de experiências extraordinárias que se complementam pela dissociação" (Rust 2013: p. 101). Assim, pelo estabelecimento dessas duas dimensões opostas, o puro realça o impuro. Mais relevante é dizer que esse contraste é decorrente da ação humana e suas razões sociais, "as crenças e os comportamentos encaixam-se para gerar alguma utilidade social ou não fazem sentido" (Rust 2013: p. 102).

Segue-se por Eliade e a hierofania. O sagrado seria aquilo que se revela aquilo que se "mostra como algo absolutamente diferente do profano". Entretanto este conceito não parece explicar muito e nem oferecer qualquer auxílio na identificação do que é ou não sagrado, ou ainda, qualquer ferramenta para análise ou, como bem salienta Rust, é uma definição que "por pouco não se tornou uma forma retórica pouco propícia à análise". Em termos de construção do conhecimento, é uma colocação que eu diria ser impossível de se verificar ou negar.

Para Rudolf Otto, o sagrado é representado pelo termo numinoso. É o sentimento de criatura, de estar cercado por algo que não se compreende, cercado de mistério. É o sentimento arrebatador de se sentir inferior e dependente até a medula de algo maior, supremo, majestático. Sua definição se aproxima da de Eliade por descrever algo que não exatamente auxilia na análise, porém seu conceito oferece algumas pistas mais concretas. $\mathrm{O}$ seu numinoso é algo que promove impulsos da ação da psique humana e, em especial, pelo sentimento de criatura. Neste caminho, o sagrado seria aquilo que é maior e indescritível, que impõe submissão do indivíduo. É diferente de sua relação com o Estado, a não ser, talvez, para um caso de patriotismo devocional, em que de fato o amor à pátria a soergue a níveis sobrenaturais.

Roger Caillois percebe o sagrado com uma natureza extremamente móvel. É algo reversível. O que é sagrado pode deixar de sê-lo e o que é profano pode tornar-se sagrado. Seu conceito conecta-se com o "devir social e considera que nada há que não possa tornar-se sua sede e revestir-se assim aos olhos do indivíduo ou da coletividade de um prestígio sem igual. Nada há, igualmente, que não possa ver-se desapossado dele"; "é uma qualidade que as coisas não possuem por si mesmas". Isso poderia soar com um ar de artificialidade ou superficialidade, mas para Caillois o sagrado é extremamente poderoso, sua eficácia é muito 
grande, ainda que defina o sagrado como "uma energia perigosa, incompreensível, arduamente manejável, eminentemente eficaz”. Aqui uma nova dualidade e de inegável relevância.

O sagrado é eficaz - o sagrado se relaciona com o devir social, ao mesmo, a sua energia, aquilo que o configura e faz mover as pessoas, não é completamente compreensível, mas é eficaz em conduzir a adesão a ações, comportamentos - mas o sagrado é dificilmente manejável. Não é um conjunto de botões e alavancas que o agente histórico moverá a seu bel prazer, sendo que essa força eficaz também exerce controle sobre aquele que planeja utilizálo. No caso do discurso soteriológico contido nos manuais portugueses de bem morrer, na era moderna, percebe-se que a escolha de preces adequadas para se esperar à morte ou os exercícios mentais para se preparar são diferentes a cada escritor, atendendo a suas tendências e interesses. Mas entre eles existem limites, como a própria necessidade dos sacramentos, as indulgências ou mesmo a existência do purgatório. Lutero é um exemplo daqueles que promoveram mudanças, ou que significaram e simbolizam um momento de mudanças, no seio de uma concepção de sagrado e as consequentes rupturas em níveis profundos. A ruptura protestante indicar que a alteração pode ser promovida, o sagrado pode ser manejável, mas com grande esforço.

Creio que muitos conceitos diferentes foram expostos, alguns mais claros, outros menos. Talvez seja o tempo de conciliar essas ideias. Ao longo da escrita, busquei fazer considerações sobre aquilo que os autores tratados ofereceram. Conjugarei, agora, este conjunto de pensadores, em busca da conciliação de um conceito, que seja o mais preciso possível e capaz de oferecer suporte à pesquisa desenvolvida.

Parece-me claro que o sagrado não é uma força estática. Como Caillois ensinou, o sagrado se modificará conforme as transformações sociais. Isto também era preconizado por Durkheim: o sagrado possui uma relação com a razão social. Abandonarei, entretanto, a dualidade de Durkheim sobre forças benfazejas e más, ainda que possam dizer algo sobre a percepção do bem e mal, uma vez que demandaria maiores reflexões sobre o conteúdo semiótico que apresenta.

Mas se a razão social se transforma e com ela o sagrado, como se maneja esta operação? Rodrigues nos fala sobre a utilização da Igreja do sentimento de medo para conduzir a um conjunto de práticas de adesão aos ditames doutrinais, entretanto não nos fala sobre o como. Seriam essas mudanças conforme postuladas por Ariès, entre o cultural e o biológico, conduzidas por motores mais secretos? Ou a resposta residiria mais próxima da 
ação humana do evento, em que o indivíduo e seus grupos conseguem alterar a direção da fé e da relação com o sobrenatural?

Parece-me ser uma questão sobre consciência. Pois mesmo para Ariès, é óbvio que a mudança decorre dos agrupamentos humanos, das sociedades, dos indivíduos, mas seu questionamento é que talvez aquilo que consideramos a ação eficaz humana que promove mudança seja na verdade mero efeito demonstrador da mudança já ocorrida ou em evolução. Aquilo que observamos é na verdade indicador. Neste sentido, não consigo aderir completamente a esta tese.

Ainda que seja possível considerarmos que existem correntes mais duradouras de expressão, mentalidades que atravessarão séculos e que será lentamente transformado, o tempo histórico não poderia aceitar ser reduzido a apenas essas grandes correntes. Seria uma espécie de estruturalismo que teria como base esses motores secretos e cogito ser a realidade mais dinâmica que isto. Rust melhor dirá:

O sagrado não é estático, inato ou definitivo, uma vez que deriva da busca por referenciais simbólicos plenos, que proporcionem experiências de segurança em face das tensões e dos riscos impostos pela vida em sociedade. O raciocínio que se desenha é este: existindo no tempo, a realidade social muda sem cessar; as mudanças trazem novos riscos e tensões; inéditas, as instabilidades exigem do sagrado outras respostas(Rust 2013: p. 104)

Retornando meu problema mais geral de pesquisa, a morte e o discurso sobre a morte. A morte é uma situação eminentemente social. Remove um componente da sociedade gerando efeitos imediatos e irreversíveis. Os perigos inerentes são muitos. A morte pode significar o desequilíbrio econômico, a falta de sustento material, pode significar a quebra de uma rede solidária. Em um aspecto mais humano, desencadeia os mais diversos sentimentos de desespero e perda. Aceitando o risco de uma interpretação por demais funcional, o sagrado terá, sim, uma presença a oferecer soluções para essas incertezas, oferecendo caminhos normatizantes que "remendarão" o machucado na tessitura social. Novamente com Rust, o “sagrado é a transfiguração simbólica da ação socialmente eficaz” (Rust 2013: 105).

Mas resta saber se o sagrado se relaciona com o universo exclusivamente sobrenatural. Seria possível encontrar o sagrado no secular? Creio não ser possível encerrar com uma conclusão, não ao menos ainda. A primeira intuição seria dizer que não. Porém, se não nos orientarmos por uma lógica idealizadora do que seja a secularização, do que seja a manutenção das funções sociais por corpos civis, não religiosos, corpos do Estado ou não, não seria possível visualizar espaços de sagrado ainda no Estado laico? Transfigurações 
simbólicas de ação socialmente eficazes? A crença na democracia como solução dos problemas não representaria forças benfazejas de Durkheim? A corrupção, a utilização da máquina pública para fora de seu papel esperado, não seria uma potência negativa indeterminada, quase que dotada de uma existência própria? São apenas suposições, reflexões ao final de outras reflexões.

\section{Referências Bibliográficas}

Ariès, Philippe. 2012. História Da Morte No Ocidente: Da Idade Média Aos Nossos Dias. Translated by Priscila Viana de Siqueira. Rio de Janeiro: Nova Fronteira.

Bonucci, Antonio Maria. 1701. Escola de Bem Morrer: Aberta a Todos Os Chistãos, \& Particularmente Aos Moradores Da Bahia Nos Exercicios de Piedade, Que Se Practicañ Nas Tardes de Todos Os Domingos Pelos Irmãos Da Confraria Da Boa Morte, Instituída Com Authoridade Apostholica Na Igreja Do Collegio Da Companhia de Jesus. Lisboa: na Officina de Miguel Deslandes.

Elias, Norbert. 2001. A Solidão Dos Moribundos: Seguido de “Envelhecer E Morrer”. Rio de Janeiro: Zahar.

Ginzburg, Carlo. 2006. O Queijo E Os Vermes: O Cotidiano E as Idéias de Um Moleiro Perseguido Pela Inquisição. Translated by Maria Betânia Amoroso and José Paulo Paes. São Paulo: Companhia das Letras.

- 2010. Os Andarilhos Do Bem: Feitiçaria E Cultos Agrários Nos Séculos XVI E XVII. São Paulo: Companhia das Letras.

— 2012. História Noturna. São Paulo: Companhia das Letras.

Rodrigues, Cláudia. 2005. Nas Fronteiras Do Além: A Secularização Da Morte No Rio de Janeiro (séculos XVIII E XIX). Rio de Janeiro: Arquivo Nacional.

Rust, Leandro Duarte. 2013. A Reforma Papal (1050-1150): Trajetórias E Críticas de Uma História. Cuiabá: EdUFMT.

Vovelle, Michel. 2010. As Almas Do Purgatório, Ou, O Trabalho de Luto. Translated by Aline Meyer and Roberto Cattani. São Paulo: Editora UNESP. 